\title{
Too much and not enough
}

\author{
Rain and drought have seized the world's attention, showing the importance of water studies for society. But what if \\ the field is not pursuing the most critical research?
}

h he availability, danger and uncertainty of water has been a critical topic for humans since civilization began; in fact, the history of complex society is a history of solving the 'water question'. Some of the longest-lasting ancient infrastructure that still exists was built expressly for transporting water for cities or agriculture or for managing flooding, a sign of how much engineering, resources and planning had to be devoted, in times and places with finite amounts of each, to ensuring stable access to or protecting ourselves from water. Water studies as an academic discipline is a natural outgrowth of how much the water question, and its consequences, has influenced thinking in multiple fields from engineering and hydrology to law and sociology. The past few decades have seen an explosion of original research, not just extensive mapping and assessments of global water availability, disaster risks and the changing conditions that could alter both, but also new paradigms, such as the food-energywater (FEW) nexus, for how to think about the water that we both need and fear. We now view water as a dynamic resource that is as much a function of social, economic and political choices as it is a geological and hydrological reality of life.

However, in recent years, some scholars have started to wonder if water studies research has become a bit, well, stagnant. No doubt the level of scholarship remains extremely high throughout the field and the data being produced on a constant basis help shape critical decisions around the world. But as we at Nature Sustainability have entered our fifth year of handling manuscripts, we are increasingly facing referees' frustrations with the thematic repetitiveness of studies, even to the point of them refusing to review articles because they have seen the same type of analysis too many times before.

To be sure, this affects all fields and disciplines to a degree; paradigms and data sources have a way of driving research until seemingly every nook and cranny has been covered multiple times. But within water studies, the effect seems to be more pronounced, and conversations with some senior scholars have revealed several potential explanations. Footprint analyses of embodied water, basin mapping and flood risk impacts are all critical issues for water studies and society as a whole, but the volume of manuscripts - many of which simply compare or validate existing models without proving the claimed novel insights - risks swamping the studies that do attempt to push the field forward through unique conceptual advances and theoretical innovation.

A major issue shared by scholars is the increasing pressure of publishing. Researchers may find it easier, or are more incentivized, to write and publish papers with already existing data, models or remote-sensing platforms rather than take the time to invest in new questions and theoretical approaches. One researcher shared with us the fact that doctoral students who ten years ago would have taken their dissertation and turned it into one publication, are now expected, or even required, to squeeze three to five publications out of it. The pressure on young career scholars has never been more immense and is likely unsustainable for themselves and the discipline.

A related aspect is the role of funding in driving and supporting water research. As expected, major funding organizations and institutions will want to know and see direct applications of the research they're paying for, and likely the sooner the better; the demands of both time and practicality are probably not hospitable to furthering novel basic research within a discipline as timeless as water studies, nor the development of intriguing interdisciplinary frameworks that would require lots of collaboration to even get off the ground. Equally, a paradigm such as the FEW nexus - may monopolize funding because it is 'trending' among both administrators and policymakers, eager to capitalize on the concept at the expense of other worthy approaches and even though the nexus was never intended to be a universal framework for every situation. If you have a hammer, everything starts to look like a nail.

But even with all of this in mind, there may be a deeper and more problematic dimension behind the current obsession with continuing to submit and publish analyses in areas whose parameters are already widely established within the literature. We share the concern that water studies as a field may have largely given up on historical context and institutional change, suggesting that as water studies has become more quantified and technically driven, it has also become less grounded. While publishing more about how humans use water, scholars may have become less interested in or capable of researching how humans see water as a resource or threat. Engineering solutions to water problems are portrayed in elegant terms that may appear simple and make us feel better, precisely because they ignore the messy institutions, norms and processes that underlie our relationship, as individuals and as a society, with water in the first place. In a world suffering, as we speak, from increasing threats of both too much water and not enough at the same time, water studies needs to confront the reality that it may be pursuing too many publications and not enough ideas; this is an untenable model for the field and a potential danger to society.

We at Nature Sustainability hope to receive feedback about some of what we have raised and suggested here. More broadly, we hope to stimulate the water studies community to reflect and discuss their future development. Because right now, the best thing we can do to figure out where water studies is and where it wants to go is to talk. Perhaps over a drink.

Published online: 17 August 2021 https://doi.org/10.1038/s41893-021-00766-8 